\title{
Analysis of the biomass gasification-based shape of the crematory's secondary chamber by using Computational Fluid Dynamics
}

\author{
Yaowateera Achawangkul ${ }^{1}$, Naoki Maruyama ${ }^{1}$, Masafumi Hirota ${ }^{1}$, \\ Chatchawan Chaichana ${ }^{2}$ and Twarath Sutabutr ${ }^{3}$ \\ ${ }^{1}$ Graduate School of Engineering, Mie University, 1577 Kurimamachiya-cho, Tsu, Mie, 514-8507, JAPAN \\ ${ }^{2}$ Department of Mechanical Engineering, Faculty of Engineering, Chiang Mai University, THAILAND \\ ${ }^{3}$ Department of Alternative Energy Development and Efficiency, Ministry of Energy, Bangkok, THAILAND
}

\begin{abstract}
This paper describes the simulation result of biomass gasification-based crematory's secondary combustion chamber via CFD analysis. The chamber models, which were rectangular and cylinder type, were implemented, whereas ANSYS FLUENT with standard k-omega viscous model and SIMPLE algorithm were taken place. The results show that an average residence time of gas and particle if simulating by using rectangular chamber displays as 2 and 3 second, respectively, whereas the average residence time of cylinder chamber type presents 2 second for particle and 4 second for gas. Furthermore, the residence time of cylinder chamber type can be increased by lengthening the chamber's height, which the benefits, such as efficient pollution control, will be earned.
\end{abstract}

Keywords: - Biomass, Computational Fluid Dynamics, Cremation, Gasification, Producer Gas, Residence Time

\section{INTRODUCTION}

A double-chambered crematory has been widely introduced, due to its efficiently pollution control and combustion performance promotion. This crematory's type consists of two main chambers: the primary chamber is used to burn human corpse and coffin, and the secondary chamber is used to eliminate dust particle and combustion gas released from the primary chamber before exhausts to the atmosphere. Generally, petroleum fuels, such as diesel oil or liquefied petroleum gas, are used as main fuel in cremation process. However, the operation cost per each cremation becomes higher due to the increasing price of global petroleum. Hence, research and study for alternative energy application for cremation should be carried out.

Biomass gasification is a thermo-chemical conversion process that turns organic fuels into gaseous compounds (called producer gas or syngas) by supplying oxygen, of which less is needed, to complete fuel combustion. The main product of the syngas contains flammable gas such as carbon monoxide (CO), hydrogen $\left(\mathrm{H}_{2}\right)$ and some traces of methane $\left(\mathrm{CH}_{4}\right)$, which can be used as fuel in a gas engine for electricity generation or heat production in a small or medium scale factory[1]. Owing to the biomass producer gas that can be combusted more easily than solid biomass, it is possible to apply biomass gasification for cremation, especially in the double-chambered crematory.

The secondary combustion chamber, as described earlier, plays an important role for emission elimination occurred from cremation before exhaust to the outside, thus, it is necessary to conduct the simulation of combustion and flow characteristics inside the chamber. Accordingly, Computational Fluid Dynamics (CFD) analysis was applied in this research. Due to the study of S. Thavornun[2], the temperature of this chamber must be maintain at above $920 \mathrm{~K}$ that the gas causing of unpleasant odor will be destroyed.

Y. Achawangkul et.al.[3] have analyzed combustion characteristics inside the double-chambered crematory using biomass producer gas as fuel by using CFD and found that the angle of primary burner should be 25 degree downward with the air nozzles' angle should be is 30 and 30 degree along the z-axis and $\mathrm{y}$-axis respectively. By these conditions, the maximum temperature of the primary chamber was $1,700 \mathrm{~K}$, while the temperature inside the secondary chamber achieved 1,300 $\mathrm{K}$ approximately.

W. Bubpamala [4] has used CFD to analyze the shape of energy-saving crematories using diesel oil as fuel. The results showed that the crematory in which the secondary chamber is installed above the primary chamber can achieve higher efficiency.

\section{RELATED EQUATIONS}

\subsection{Governing equations}

Fundamental governing equations used for simulation were Navier-Stokes Equations, which consist of mass conservation and momentum conservation.

$$
\frac{\partial \rho}{\partial t}+\nabla \cdot(\rho \vec{V})=0
$$




$$
\begin{aligned}
& \frac{\partial(\rho u)}{\partial t}+\nabla \cdot(\rho \vec{V} u)=\frac{\partial\left(-P+\tau_{x x}\right)}{\partial x}+\frac{\partial \tau_{y x}}{\partial y}+\frac{\partial \tau_{z x}}{\partial z}+\rho f_{x} \\
& \frac{\partial(\rho v)}{\partial t}+\nabla \cdot(\rho \vec{V} v)=\frac{\partial \tau_{x y}}{\partial x}+\frac{\partial\left(-P+\tau_{y y}\right)}{\partial y}+\frac{\partial \tau_{z y}}{\partial z}+\rho f_{y} \\
& \frac{\partial(\rho w)}{\partial t}+\nabla \cdot(\rho \vec{V} w)=\frac{\partial \tau_{x z}}{\partial x}+\frac{\partial \tau_{y z}}{\partial y}+\frac{\partial\left(-P+\tau_{z z}\right)}{\partial z}+\rho f_{z}
\end{aligned}
$$

2.2 Heat transfer model

An energy conservation equation was used for heat transfer inside a control volume prediction.

$$
\frac{\partial}{\partial t}\left(\rho c_{p} T\right)+\frac{\partial}{\partial x}\left(\rho u c_{p} T\right)+\frac{\partial}{\partial y}\left(\rho v c_{p} T\right)+\frac{\partial}{\partial z}\left(\rho w c_{p} T\right)=k\left\{\frac{\partial^{2} T}{\partial x^{2}}+\frac{\partial^{2} T}{\partial y^{2}}+\frac{\partial^{2} T}{\partial z^{2}}\right\}+q^{\prime \prime \prime}
$$

2.3 Standard $k-\omega$ models

Standard $k-\omega$ models [5] were applied in this research, which are represented in (6)-(7).

$$
\begin{aligned}
\frac{\partial}{\partial t}(\rho k)+\frac{\partial}{\partial x_{i}}\left(\rho k u_{i}\right) & =\frac{\partial}{\partial x_{i}}\left[\left(\mu+\frac{\mu_{t}}{\sigma_{k}}\right) \frac{\partial k}{\partial x_{j}}\right]+G_{k}-Y_{k}-S_{k} \\
\frac{\partial}{\partial t}(\rho \omega)+\frac{\partial}{\partial x_{i}}\left(\rho \omega u_{i}\right) & =\frac{\partial}{\partial x_{i}}\left[\left(\mu+\frac{\mu_{t}}{\sigma_{\omega}}\right) \frac{\partial \omega}{\partial x_{j}}\right]+G_{\omega}-Y_{\omega}-S_{\omega}
\end{aligned}
$$

where $G_{k}$ represents the generation of turbulent kinetic energy that arises due to mean velocity gradients, and $G_{\omega}$ is the generation of $\omega . Y_{k}$ and $Y_{\omega}$ represent the dissipation of $k$ and $\omega$ due to the turbulence, whereas $S_{k}$ and $S_{\omega}$ are defined source terms.

The turbulent viscosity was defined using a damping coefficient $(\alpha *)$.

$$
\mu=\alpha * \frac{\rho k}{\omega}
$$

\subsection{SIMPLE algorithm}

Because the flow inside the crematory mainly follows the implicit non-linear Navier-Stokes Equations, the wellknown Semi-Implicit Method for the Pressure-Linked Equation (SIMPLE) algorithm was used to solve for the model's velocity flow field [6].

\section{METHODOLOGIES}

SolidWorks was used to implement the crematory model. The primary chamber had a total volume of $2.03 \mathrm{~m}^{3}$. Five auxiliary air nozzles were arranged on both the left and right sides of the chamber, with incline angles of 30 degrees along both the $z$-axis and $y$-axis. On the chamber's backside wall, the primary producer gas burner was placed at a 25-degree downward angle in order to provide maximum impingement of the flame onto the coffin and corpse.

Concerning the secondary combustion chamber's model, the shapes were classified into two types: rectangular and cylinder. Regarding the rectangular shape, the chamber's volume was $2.0 \mathrm{~m}^{3}$, while a U-shape was introduced for efficient dust particle precipitation. Figure 1 shows the implemented crematory's model with the secondary chamber with a rectangular shape.

For the cylinder-type secondary chamber, the total volume was equal to $0.78 \mathrm{~m}^{3}$, with a diameter of 1.0 $\mathrm{m}$, and a height of $1.0 \mathrm{~m}$. One of these types of chambers was located above the primary chamber (Model $\mathrm{C} 1$ ), in which the gas flow (combustion gas and particle) released from the primary chamber was injected at the bottom of the secondary chamber, as shown in Fig. 2(a). The other chamber was located beside the primary chamber (Model C2), so that gas flow from the primary chamber would be injected beside the cylinder secondary chamber, as shown in Fig. 2(b).

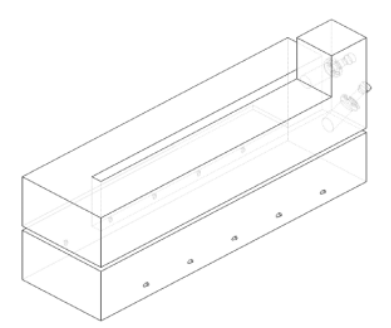

Fig.1 Crematory's model with a rectangular-prism secondary chamber 


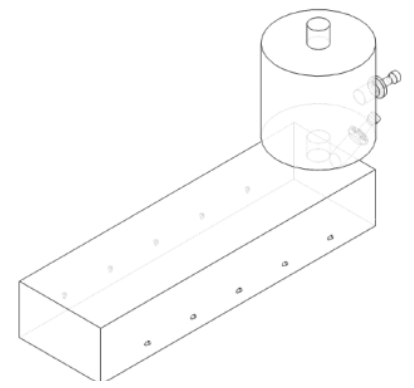

(a) Secondary chamber located above the primary chamber (Model C1)

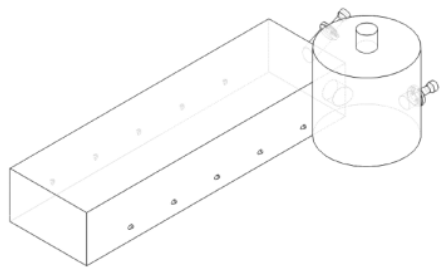

(b) Secondary chamber located beside the primary chamber (Model C2)

Fig.2 Location of the cylinder-type secondary chamber

After the model implementation, ANSYS FLUENT was used to simulate flow characteristics inside the model. A pressure outlet boundary condition was applied to the outlet and the walls were treated at a constant wall temperature or adiabatic wall temperature. The wall was assumed to be stationary with non-slip conditions applied to the wall surface $\left(V_{x}=V_{y}=V_{z}=0\right)$. The boundary conditions of simulation are presented in Table 1 .

Table 1 Boundary conditions input for the crematory simulation

\begin{tabular}{|l|c|}
\hline Velocity of producer gas at $1^{\text {st }}$ burner & $5.0 \mathrm{~m} / \mathrm{s}$ \\
\hline Velocity of producer gas at $2^{\text {nd }}$ burner & $5.0 \mathrm{~m} / \mathrm{s}$ \\
\hline Velocity of air injected into $1^{\text {st }}$ burner & $5.6 \mathrm{~m} / \mathrm{s}$ \\
\hline Velocity of air injected into $2^{\text {nd }}$ burner & $5.6 \mathrm{~m} / \mathrm{s}$ \\
\hline Velocity of primary chamber auxiliary air & $20.0 \mathrm{~m} / \mathrm{s}$ \\
\hline Temperature of producer gas & $300 \mathrm{~K}$ \\
\hline Temperature of combustion air & $300 \mathrm{~K}$ \\
\hline
\end{tabular}

\section{RESULTS AND DISCUSSION}

\subsection{Temperature contours}

Figure 3 shows the temperature contour of each secondary chamber type. The simulation shows that the maximum temperature of the rectangular chamber (Model A) occurred at approximately 1,700 $\mathrm{K}$, as shown in Fig. 3(a), while the average temperature throughout the chamber was 1,300 K.

For the temperature inside the cylindrical chamber, when the secondary chamber was located above the primary chamber (Model C1), the average temperature reached 1,300 K. From Fig. 3(b) as well as Model C2, it can be observed that the highest temperature occurring inside the secondary chamber is influenced by the heat released from primary chamber combustion. These phenomena contribute to the merit of the combustion inside the secondary chamber, which reduces the fuel input at the secondary burner in order to maintain the temperature of the chamber at the highest point.

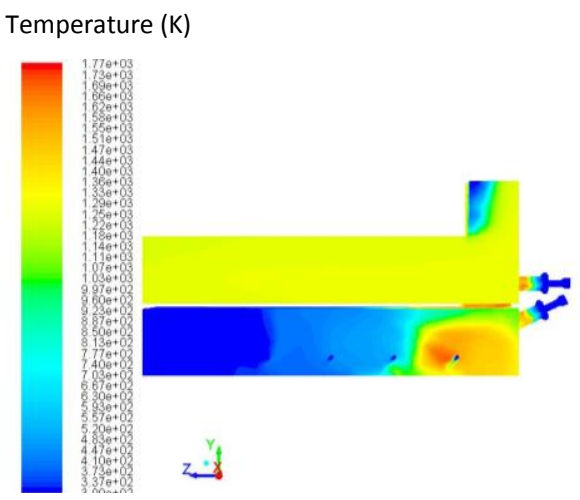

(a) Model A
Temperature (K)

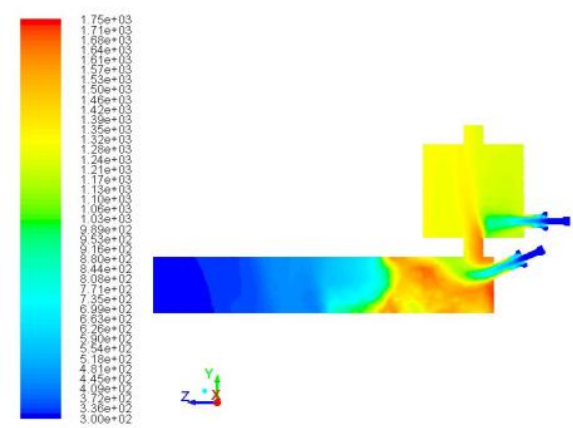

(b) Model C1 
Temperature (K)

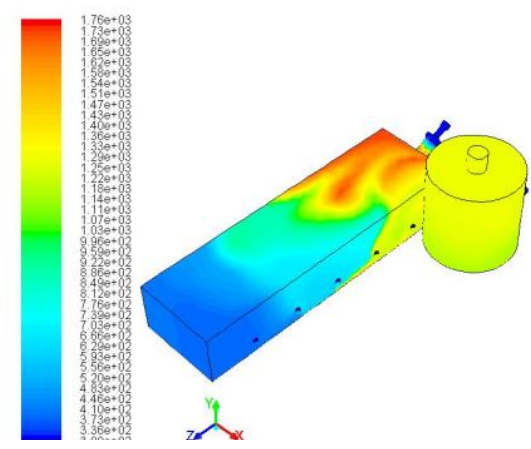

(c) Model C2

Fig.3 Temperature contour inside the crematory models

\subsection{Velocity and turbulent scheme}

Figure 4 presents the distribution of the velocity vector inside the Model A crematory. The velocity at the secondary chamber's entrance becomes mainly $2.5 \mathrm{~m} / \mathrm{s}$ until reaching the U-shaped turning point. After that, a majority of the velocity increases to approximately $7 \mathrm{~m} / \mathrm{s}$, and gradually increases before exiting the crematory's stack. The occurring velocity in the stack is $8.5 \mathrm{~m} / \mathrm{s}$.

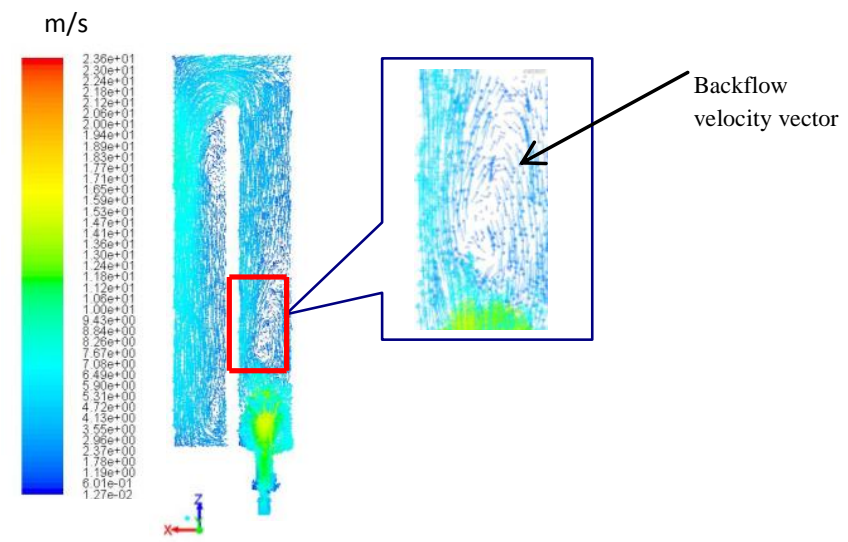

Fig.4 Velocity profile and backflow of Model A

In addition, the backflow occurring at the chamber's inlet could be investigated. This result explains the efficient swirling of the gas flow, which can also increase the residence time of the chamber's exhaust gas flow.

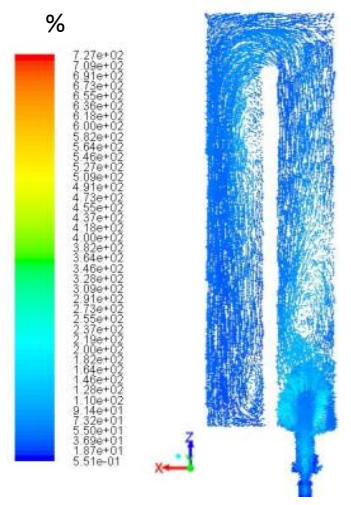

Fig.5 Turbulent intensity distribution inside Model A

The result of the turbulent intensity is shown in Fig. 5. The turbulent intensity inside the chamber before reaching the turning point was approximately $60 \%$. Likewise, the turbulent intensity decreased to $30 \%$ in 
the stack. The result of the high turbulent intensity occurring in this type of chamber contributed to the effectiveness of combustion gas circulation, also resulting in efficient dust particle impingement at the chamber's wall that could decrease the amount of particles released into the atmosphere.

The velocity simulation results when using Model C1 are shown in Figs. 6(a) and 6(b). It was observed that the generality of the model's velocity profile was a radial velocity, which became $20 \mathrm{~m} / \mathrm{s}$ in the middle of the chamber, while the radial velocity beside the chamber's core measured as $2.0-3.0 \mathrm{~m} / \mathrm{s}$. The axial velocity, on the other hand, resulted in $2.0 \mathrm{~m} / \mathrm{s}$ in the middle of the model.

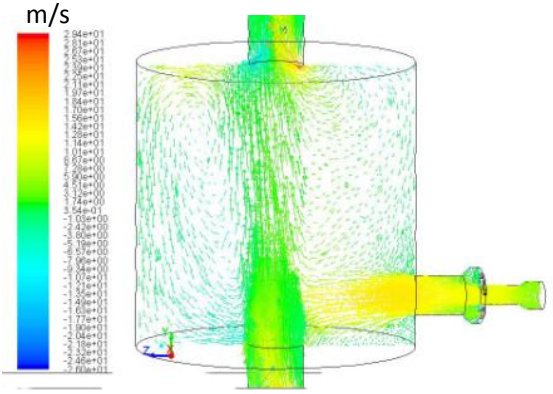

(a) Model C1

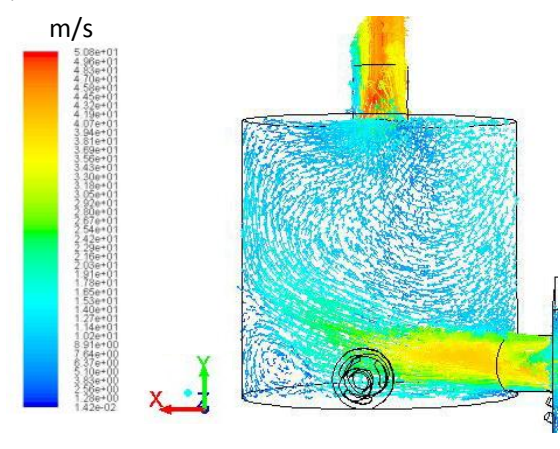

(b) Model C2

Fig. 6 Velocity profile of models $\mathrm{C} 1$ and $\mathrm{C} 2$

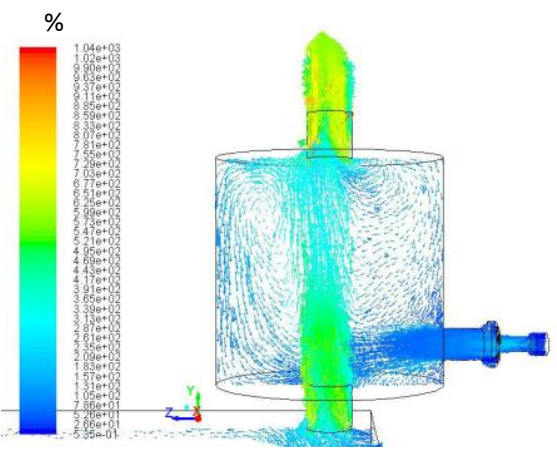

(a) Model C1

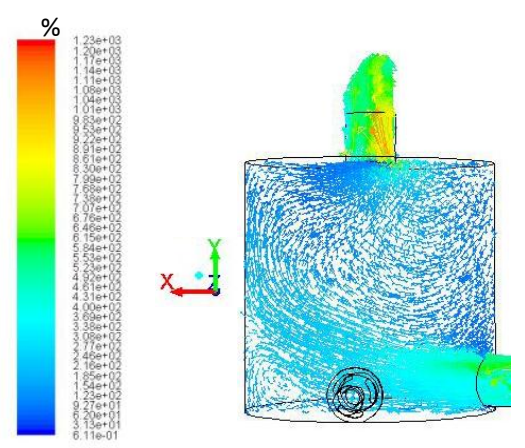

(b) Model C2

Fig. 7 Turbulent intensity of models $\mathrm{C} 1$ and $\mathrm{C} 2$

Concerning the turbulent intensity scheme of this model (Fig. 7), it can be observed that Model C2 performed at a higher turbulent intensity compared to Model $\mathrm{C} 1$, because the majority of the flow inside Model $\mathrm{C} 2$ showed a centrifugal shape.

\subsection{Residence time}

The residence time represents the time allotted for the combustion process to be completed while the gas levels are maintained [7]. The constituents of combustion gas, especially during cremation, contain dust particles, soot, toxic gas and an unpleasant odor. The secondary combustion chamber, therefore, is necessary to eliminate this matter by the proper residence time. The residence time of the crematory's secondary chamber must be at least 1 second in order to prevent emissions from being released into the atmosphere [8].

Simulation of the secondary chamber's residence time assumed that the dimension of particles released from the primary chamber has a $1 \mu \mathrm{m}$ diameter. The residence time observation occurred from when the particles were starting to exit the inlet of the secondary chamber until they reached the stack.

Figure 8 presents the results of the residence time of the rectangular-shaped secondary chamber. It was found that the residence time of the gas flow inside the chamber was $2.54 \mathrm{~s}$ on average, whereas the average residence time of the particle was $3.05 \mathrm{~s}$. This chamber's type was beneficial due to its long length, allowing an increase in the residence time. 
Second

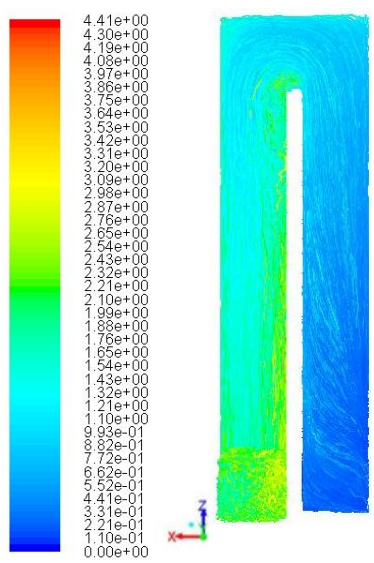

(a) Particle residence time

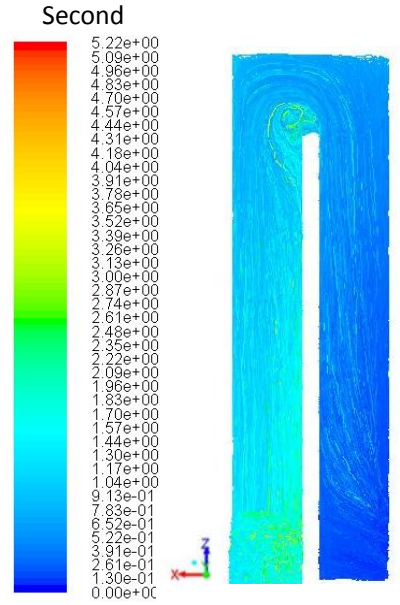

residence time

Fig. 8 Simulation results of the residence time of Model A
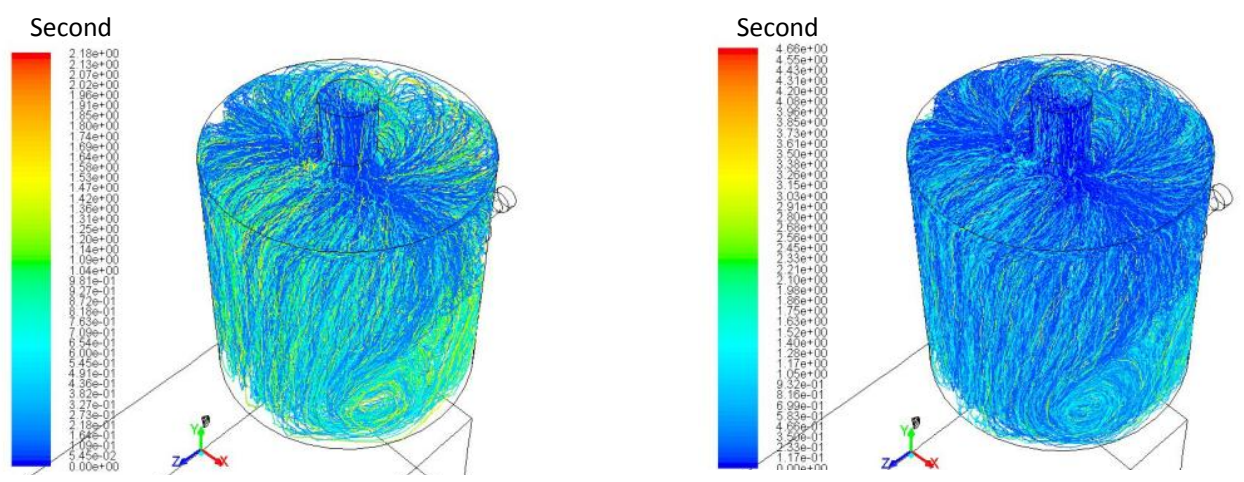

Fig. 9 Simulation results of the residence time of Model C1

For the cylinder-type chamber, it was investigated that if the secondary chamber was located above the primary chamber (Model $\mathrm{C} 1$ ), the maximum residence time of particles occurred at $2.18 \mathrm{~s}$, and the average particle's residence time was $1.20 \mathrm{~s}$, as shown in Fig. 9. These residence time phenomena could explain why the majority of the flow inside the chamber presented a radial flow, and thus, both the released combustion particles and gas flow behavior were swirled causing a residence time increase.

Concerning the simulation results of Model C2 (Fig. 10), it was found that this chamber's type resulted in a shorter residence time compared with the residence time of Model $\mathrm{C} 1$. For this model, the average residence time of particles and gas results were 0.70 and $1.02 \mathrm{~s}$, respectively. These results occurred because the position of the chamber's inlet was located beside the main combustion chamber, forcing gas and the particle flow to be mixed. However, most particles and gas revealed only a few swirling flows before exiting the stack, and thus caused a shorter residence time.

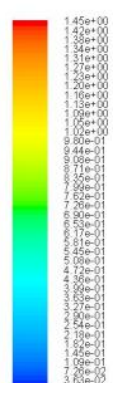

(a) Particle residence time

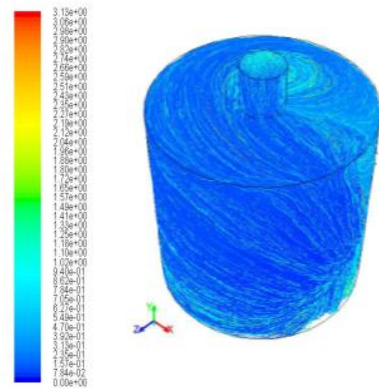

(b) Gas residence time Fig. 10 Simulation results of the residence time of Model C2 
The simulation of the chamber's dimensions were also carried out in this study in order to investigate the gas and particle flow behavior, and the changing of the residence time that is effected by several chamber's dimensions. Figure 11 shows a comparison of the residence times obtained from the simulation when changing the chamber's volume by increasing the chamber's height to 1.1, 1.2 and 1.3 m. The simulation results of Model C1 display a high residence time increase rate, particularly the residence time of gas that increased gradually when the chamber's height was lengthened, as well as the particle residence time. These phenomena can be explained by the increasing of the chamber's volume by extending the height, which allowed gas and particles to be maintained in the chamber for a longer time.

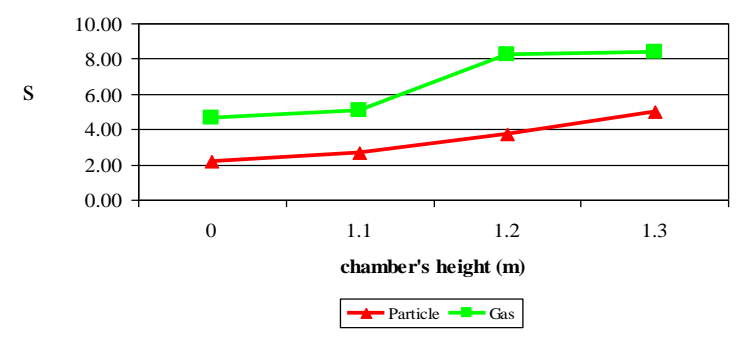

(a) Model C1

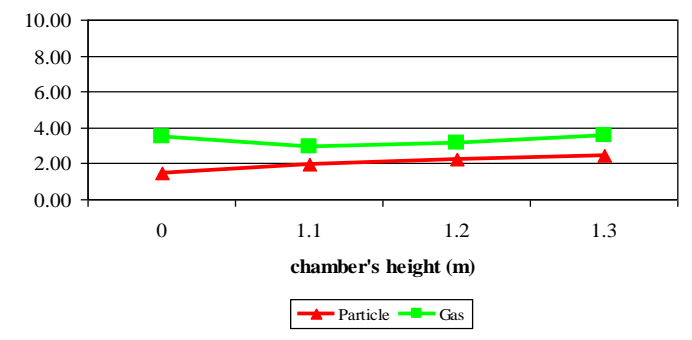

(b) Model C2

Fig. 11 Simulation results of the residence time when increasing the chamber's volume

Concerning Model C2, it could be observed that the majority of the residence time became rather constant, especially the residence time of gas. The particle residence time, on the other hand, resulted in a small increase, which reached a maximum of $2.5 \mathrm{~s}$ when the height was adjusted to $1.3 \mathrm{~m}$. This model's results can be explained by the increase in the chamber's height, which affected the circulation of particles; thus, the simulated residence time of particles became higher. In contrast, most combustion gas flow behavior did not achieve a circulation flow. Consequently, the trend of the gas's residence time when simulated by Model C2 was fairly constant.

\section{CONCLUSION}

Besides the temperature inside the crematory's chamber that must be maintained at a high point, the residence time of the secondary chamber, which must be at least 1.0 second, according to pollution control regulations, plays an important role to prevent emissions from being released into the atmosphere during cremation. Moreover, the pollution elimination efficiency of the crematory will increase if the residence time increases. From the simulation results, it can be found that the rectangular type of chamber presents the highest residence time due to its longer length. On the other hand, the cylinder type, in which the combustion gas and particle inlet are located at the chamber's base, can achieve a more efficient residence time compared with the rectangular shape. In addition, the cylinder-shaped chamber is also advantageous in that it will be able to reduce the cremation's construction costs and simultaneously reduce the space needed for installation.

\section{ACKNOWLEDGEMENTS}

The authors would like to acknowledge the Dean of the Faculty of Engineering, Chiang Mai University, the faculty's lecturers and staff members for all their assistance during the experiment conduction, as well as Assoc. Prof. Kulachate Pienthong (Ubon Rajathani University) and Mr. Thanadej Kantachote, Manager of J.E.N. Construction CO. LTD, for all of their valuable comments and suggestions.

\section{REFERENCES}

[1] A.K. Rajvanshi, Biomass gasification, Alternative Energy in Agriculture, Vol. II, 1986, 83-102.

[2] S. Thavornun, Study and research on crematory for energy saving, Research's report, Energy Policy and Planning Office, Bangkok, Thailand, 2007.

[3] Y. Achawangkul, N. Maruyama, C. Chaichana, M. Hirota, A. Nishimura, P. Teeratitayangkul, CFD analysis of double-chambered crematories using biomass producer gas as a fuel source, Int. J. of Modern Engineering Research, Vol. 3, Issue. 6, 2013, 3493-3499.

[4] W. Bubpamala, Research and development of human crematory for energy saving, Master Degree dissertation, King Mongkutt's University of Technology North Bangkok, Bangkok, 2007.

[5] D.C. Wilcox, Turbulence Modeling for CFD (DCW Industries, Inc., La Canada, California, 1998).

[6] S.V. Patanka, Numerical heat transfer and fluid flow (Hemisphere Publishing Corporation, NY: Taylor \& Francis, 1980).

[7] F. Hasselriis, Practical design of waste incineration, Handbook of Environmental Engineering Calculations, (New York: McGraw-Hill, 2007).

[8] Pollution Control Department of Thailand, Situation of air pollution from crematory. Department publishing's document, 2005. 